\title{
Strong-wind events and their influence on the formation of snow dunes: observations from Kohnen station, Dronning Maud Land, Antarctica
}

\author{
Gerit BIRNBAUM, ${ }^{1}$ Johannes FREITAG, ${ }^{1}$ Ralf BRAUNER, ${ }^{2}$ Gert KÖNIG-LANGLO, ${ }^{1}$ \\ Elisabeth SCHULZ, ${ }^{3}$ Sepp KIPFSTUHL, ${ }^{1}$ Hans OERTER, ${ }^{1}$ Catharina H. REIJMER, ${ }^{4}$ \\ Elisabeth SCHLOSSER, ${ }^{5}$ Sergio H. FARIA, ${ }^{6}$ Hinnerk RIES, ${ }^{7}$ Bernd LOOSE, ${ }^{1}$ \\ Andreas HERBER, ${ }^{1}$ Michael G. DUDA, ${ }^{8}$ Jordan G. POWERS, ${ }^{8}$ Kevin W. MANNING, ${ }^{8}$ \\ Michiel R. VAN DEN BROEKE ${ }^{4}$ \\ ${ }^{1}$ Alfred Wegener Institute for Polar and Marine Research, PO Box 120161, D-27515 Bremerhaven, Germany \\ E-mail: Gerit.Birnbaum@awi.de \\ ${ }^{2}$ University of Applied Sciences Wilhelmshaven/Oldenburg/Elsfleth, Weserstrasse 4, D-26931 Elsfleth, Germany \\ ${ }^{3}$ Department of Physical Oceanography and Instrumentation, Leibniz Institute for Baltic Sea Research Warnemünde, \\ Seestrasse 15, D-18119 Rostock, Germany \\ ${ }^{4}$ Institute for Marine and Atmospheric Research Utrecht (IMAU), Utrecht University, PO Box 80005 , \\ 3508 TA Utrecht, The Netherlands \\ ${ }^{5}$ Institute of Meteorology and Geophysics, University of Innsbruck, Innrain 52, A-6020 Innsbruck, Austria \\ ${ }^{6}$ Center of Geosciences, Department of Crystallography, University of Göttingen, Goldschmidtstrasse 1, \\ D-37077 Göttingen, Germany \\ ${ }^{7}$ Meteorological Institute, University of Hamburg, Bundesstrasse 55, D-20146 Hamburg, Germany \\ ${ }^{8}$ Mesoscale and Microscale Meteorology Division, Earth System Laboratory, National Center for Atmospheric Research,
} PO Box 3000, Boulder, Colorado 80307-3000, USA

\begin{abstract}
Analyses of shallow cores obtained at the European Project for Ice Coring in Antarctica (EPICA) drilling site Kohnen station $\left(7^{\circ} \mathrm{O0}^{\prime} \mathrm{S}, \mathrm{00}^{\circ} \mathrm{04}^{\prime} \mathrm{E}\right.$; $2892 \mathrm{~m}$ a.s.I.) on the plateau of Dronning Maud Land reveal the presence of conserved snow dunes in the firn. In situ observations during three dune formation events in the 2005/06 austral summer at Kohnen station show that these periods were characterized by a phase of 2 or 3 days with snowdrift prior to dune formation which only occurred during high wind speeds of $>10 \mathrm{~m} \mathrm{~s}^{-1}$ at $2 \mathrm{~m}$ height caused by the influence of a low-pressure system. The dune surface coverage after a formation event varied between $5 \%$ and $15 \%$, with a typical dune size of $(4 \pm 2) \mathrm{m} \times(8 \pm 3) \mathrm{m}$, a maximum height of $0.2 \pm 0.1 \mathrm{~m}$ and a periodicity length of about $30 \mathrm{~m}$. The mean density within a snow dune varied between 380 and $500 \mathrm{~g} \mathrm{~m}^{-3}$, whereas the mean density at the surrounding surface was $330 \pm 5 \mathrm{~kg} \mathrm{~m}^{-3}$. The firn cores covering a time-span of $22 \pm 2$ years reveal that approximately three to eight events per year occurred, during which snow dunes had been formed and were preserved in the firn.
\end{abstract}

\section{INTRODUCTION}

The Antarctic ice sheet is a unique archive for climate research. During the last two decades, several deep ice cores have been drilled on the plateau of East Antarctica to reconstruct climate conditions going back 800000 years (EPICA Community Members, 2004). The drilling sites have included Vostok (Petit and others, 1999), Dome Fuji (Kawamura and others, 2007) and the European Project for Ice Coring in Antarctica (EPICA) sites Kohnen station and Dome C (EPICA Community Members, 2006; Fig. 1).

Knowledge of interactions between the atmosphere and the snow and firn layer of the ice sheet is the basis for interpretation of deep ice cores and for their use as a climate archive. Time series of a multitude of proxy parameters are derived from ice cores. Fractionation processes among the oxygen and hydrogen isotopes of water during condensation and snow crystal formation are used as proxies for temperature (Jouzel and others, 1997). Changes in the content of chemical trace elements and dust are considered as proxies for large-scale changes in atmospheric circulation
(Lambert and others, 2008), while gases in air bubbles in the ice are used to detect temporal changes in the gas composition of the atmosphere (Barnola and others, 1987). Furthermore, there are first investigations, which use structure parameters of the ice (e.g. bubble number density (Spencer and others, 2006), distribution of bubbles (Redenbach and others, 2009) and air content (Martinerie and others, 1992)) as proxy parameters for climate conditions in the past and for processes in the ice sheet. However, we still lack detailed investigations of the impact of atmospheric processes on the structure of the snowpack. To overcome this, both more glaciological investigations of the snowpack structure and more atmospheric observations need to be jointly performed.

Snow dunes of horizontal dimensions ranging from several meters to kilometers (megadunes) are a common surface feature on the Antarctic plateau. Small-scale snow dunes have been described, for example, by Koerner (1971) and Rundle (1971) at Plateau Station, by Watanabe (1978) at Mizuho plateau, by Goodwin (1990) in eastern Wilkes Land 


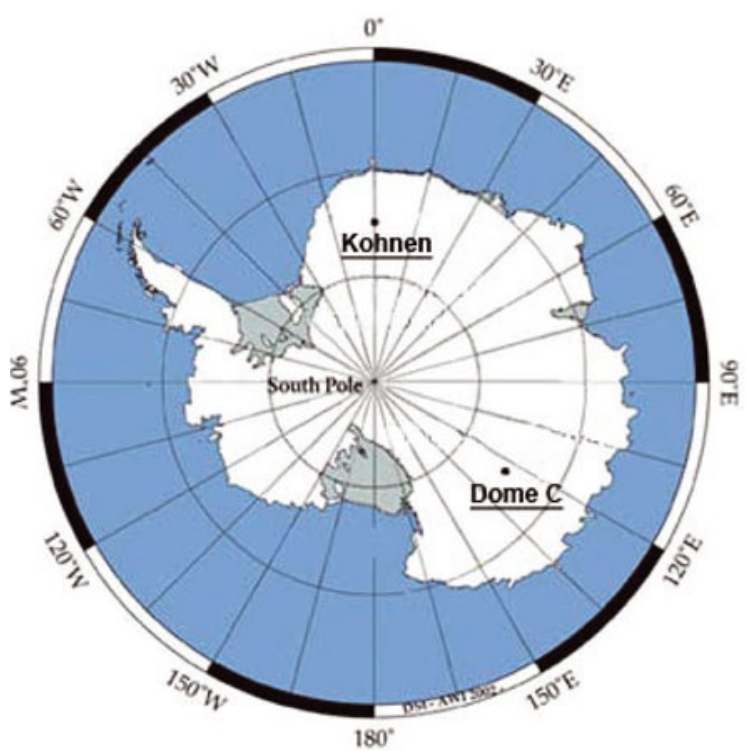

Fig. 1. Map of Antarctica showing the two EPICA drilling sites Kohnen station and Dome C.

and by Furukawa and others (1996) in Dronning Maud Land (DML). Megadune fields are observed in the interior of the East Antarctic ice sheet (Fahnestock and others, 2000; Frezzotti and others, 2002). They are mainly a result of unusually low snow accumulation and the interplay between katabatic winds and regional surface slopes.

In this study, we focus on barchans, dunes with a typical horizontal size of only several meters. A barchan dune has a crescent-shaped form with two horns pointing downwind (Fig. 2). The dune propagates downwind on a firm surface. The back of the dune is eroded by the wind; the snow transported in saltation (saltons) is deposited at the brink and is trapped on the slip-face by a recirculating flow-field bubble. The horns are formed by snow particles which are ejected as low-energy particles (reptons). At the downwind end of the horns, the snow particles can escape from the dune.

Dunes have primarily attracted the interest of researchers in the context of sand transport in deserts and for the interpretation of surface features on Mars and other planets (Bagnold, 1941; Bourke and Goudie, 2009). Most of the theoretical concepts for particle transport and dune formation are based on investigations of sand-dune dynamics (Andreotti and others, 2002).

From a glaciological point of view, there are two main reasons for a thorough investigation of small-scale snow dunes:

1. Snow dunes alter the microenvironment of the snow cover. During dune formation, surface snow is completely remixed. Particularly in low-accumulation areas on the Antarctic plateau, remixing of surface snow also means mechanical remixing of the seasonally varying aerosols within the snow. Hence, remixing changes the original chemical stratigraphy. Remixing of weathered, aged snow leads to a pore-space structure in the dunes significantly different in grain size, grain shape and connectivity, density, hardness, permeability and temperature conductivity from normally deposited snow (Freitag and others, 2008). Dunes once buried and

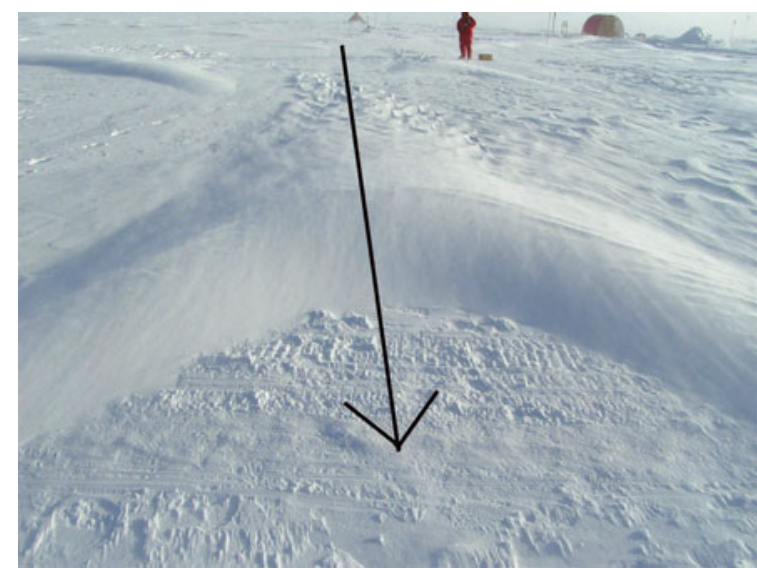

Fig. 2. Newly formed barchan-type snow dune at Kohnen station on 28 January 2006. The arrow indicates the near-surface wind direction.

preserved in the firn may influence air diffusion and air entrapment and therefore the interpretation and dating of enclosed air in polar ice cores.

2. Knowledge of the relationship between the meteorological regime on the Antarctic plateau and the number of snow-dune formation events would enable us to draw conclusions concerning meteorological conditions in the past from dune layers identified in ice cores.

Here we address the following questions: What meteorological conditions lead to the formation of snow dunes? Can dune layers survive in the firn, and how many dune layers can be identified in firn cores drilled at Kohnen station $\left(75^{\circ} 00^{\prime} \mathrm{S}, 00^{\circ} 04^{\prime} \mathrm{E}\right.$; $2892 \mathrm{ma.s.I.;}$ mean annual accumulation rate $64 \mathrm{~mm}$ w.e. $\mathrm{a}^{-1}$ (EPICA Community Members, 2006))? The formulation of criteria for the detection of dune formation events in the past is primarily based on results of combined meteorological-glaciological field studies within EPICA activities at Kohnen station in the 2005/06 austral summer and on previous investigations of the wind and precipitation regime on the Antarctic plateau.

\section{BACKGROUND}

Dunes as investigated here form during snowdrift. A snow particle becomes airborne if the wind exerts sufficient turbulent shear stress to overcome the gravitational and interparticular forces holding the particle to the surface (Mann and others, 2000). Then it is transported by the mechanism of saltation, which is the motion of particles being lifted from the ground, accelerated horizontally by the wind and then falling and repeatedly bouncing on the surface, causing other particles which they strike to be transported likewise.

Kobayashi and Ishida (1979) point out that when a layer of deposited snow is being redistributed by the wind, surface reliefs formed can be classified by depositional and/or erosional patterns. Dunes are of deposition type, because deposition is dominant. They differentiate between longitudinal dunes with a downwind-oriented main body and transverse dunes (barchans) with a main body oriented perpendicular to the wind direction. Longitudinal dunes result when wind speed exceeds $15 \mathrm{~ms}^{-1}$ at $1 \mathrm{~m}$ height (Kobayashi and Ishida, 1979), which translates into 

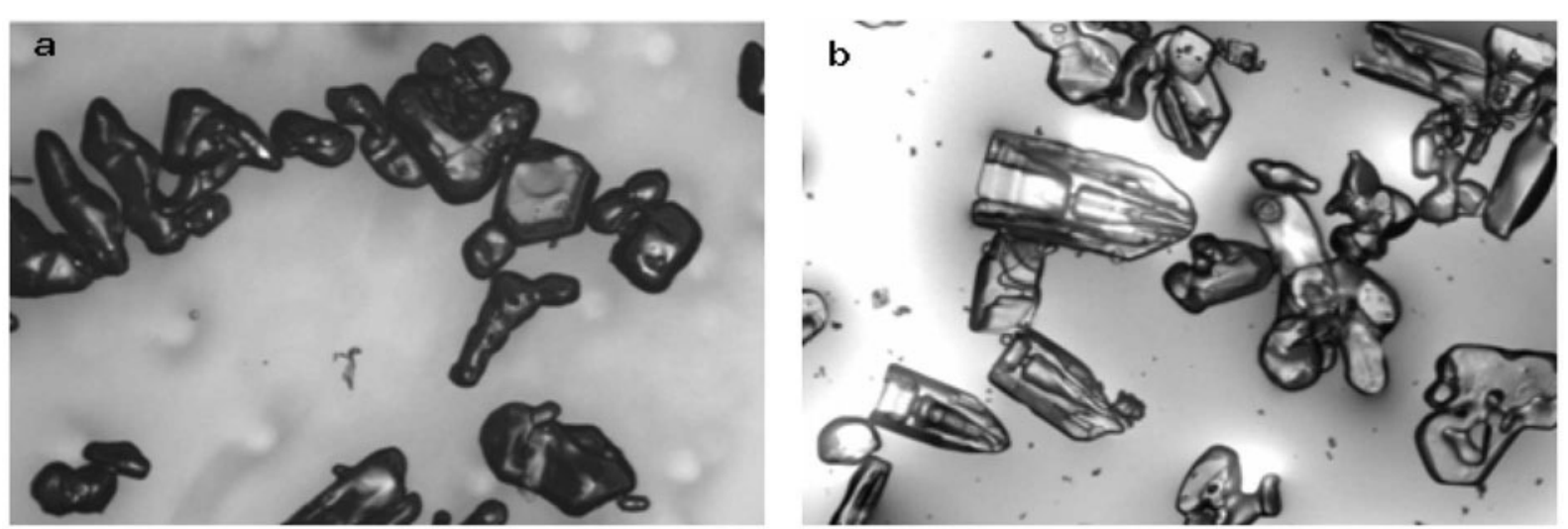

Fig. 3. Snow particles from drifting snow. (a) Particles on 9 December 2005, a day with formation of snow dunes. The width of the picture corresponds to $2.50 \mathrm{~mm}$. (b) Particles on 3 December 2005, a day without formation of snow dunes. The width of the picture corresponds to $1.25 \mathrm{~mm}$. In normal drift snow as shown in (b), the fraction of newly formed crystals (columns, bullet-type crystals or hexagonal plates) is high and appears even to be predominant. Dune snow particles as shown in (a) appear much smoother (weathered) and hardly contain newly formed crystals. Most of the dune snow particles are aged, already ejected snow grains from the former surface.

$\sim 16 \mathrm{~m} \mathrm{~s}^{-1}$ at $2 \mathrm{~m}$ height for neutral stratification, whereas transverse dunes (barchans) occur with wind speeds of $<15 \mathrm{~m} \mathrm{~s}^{-1}$ at $1 \mathrm{~m}$ height (Kobayashi and Ishida, 1979).

A first comprehensive analysis on the wind regime at Kohnen station, DML, was performed by Van As and others (2007) who focused on the meteorology of strong-wind events and on their impact on the near-surface atmosphere and climate. Van As and others (2007) point out that, by definition, strong winds have a minimum value of $10.8 \mathrm{~m} \mathrm{~s}^{-1}$ at $10 \mathrm{~m}$ height (Beaufort scale 6), which translates into wind speeds $>9.5 \mathrm{~m} \mathrm{~s}^{-1}$ at $2 \mathrm{~m}$ for neutral stratification. According to Van As and others (2007), most wind events at Kohnen station that fulfill this criterion are caused by warm-core cyclones in the northeastern Weddell Sea. The elevated Antarctic interior is shielded from cyclonic low-pressure systems by the escarpment zone (Carleton and Carpenter, 1990; Sinclair, 1994). However, the largest of the lowpressure systems can either influence the atmosphere over large areas of the interior from their coastal location or on occasion move onto the plateau (Pook and Cowled, 1999).

\section{OBSERVATIONS: MAIN CHARACTERISTICS OF SNOW DUNES}

Within the glaciological field program at Kohnen station in the 2005/06 austral summer, continuous surface and snow crystal observations were carried out together with profilings of surface density. Crystals were captured on a glass plate covered with a thin film of silicon oil and then mapped in microscopic resolution (Kipfstuhl and others, 2006). Additionally, nine shallow firn cores of 4-5 $\mathrm{m}$ depth were drilled along a $600 \mathrm{~m}$ traverse route near the station.

Three events of barchan-type snow-dune formation were observed during the work period at the station from midNovember 2005 until the beginning of February 2006, namely on 9 December 2005, 11 January 2006 and 28 January 2006. The dunes were formed during snowdrift caused by strong winds. After the snowdrift had ended, the observed barchans became very hard within a few hours; it was then possible to walk on the dunes without sinking into the snow. The dune surface coverage after each of the formation events varied between $5 \%$ and $15 \%$, with a typical dune size of $(4 \pm 2) \mathrm{m} \times(8 \pm 3) \mathrm{m}$, a maximum height of
$0.2 \pm 0.1 \mathrm{~m}$ and a periodicity length of $\sim 30 \mathrm{~m}$. A minimum dune size of $2 \mathrm{~m}$ width and $5 \mathrm{~m}$ length was observed. The mean density within a snow dune varied between 380 and $500 \mathrm{~kg} \mathrm{~m}^{-3}$, whereas the mean density of the uppermost $6 \mathrm{~cm}$ at the surrounding surface was $330 \pm 5 \mathrm{~kg} \mathrm{~m}^{-3}$.

An image of snow particles captured during snowdrift on 9 December 2005, the day of the first dune formation event observed, is shown in Figure 3a. For comparison, Figure 3b shows snow particles captured on 3 December 2005, a day with snowdrift too, but without formation of snow dunes. The difference in the type of snow particles is obvious. Characteristic of normal drift snow (Fig. 3b) is the large fraction of columns, bullet-type crystals or hexagonal plates. Such crystals either form during a snowdrift situation or remained from the last snowfall. However, often they are observed in drifting snow under clear sky. Such crystals are predominant in 'normal' drift snow. Aged and weathered snow grains or fragments of the former firn skeleton are much less abundant. The opposite is observed in dune snow. Hardly any newly formed crystals are present $(\leq 1 \%)$. Typical are rounded particles consisting of not too large fragments of the old surface snowpack. They are probably heavier and aerodynamically smoother so that they generally move close to the surface. The shapes of normal drift snow certainly favor a movement higher above the surface and already moving at comparatively low wind speeds. Furthermore, the aged and weathered snow particles of dune snow appear much more robust than the often fragile-looking crystals of normal drift snow. The differences in shape and size of the crystals explain the differences in the density of dune snow and any snow from the surrounding surface. The wind sorts and mixes these dune-snow particles so that the density of dune snow can achieve values close to that of the closestpacked structure of spheres, $550 \mathrm{~kg} \mathrm{~m}^{-3}$. Packing experiments showed that oval, disk-like particles can reach exceptionally high densities. Moreover, in closely packed snow, nearest neighbours touching each other sinter together and make the dune snow mechanically stable and exceptionally hard within a short time. We conclude that the snow dunes were formed out of old, partially sintered and redistributed snow.

Dune layers from past formation events were detected in the nine firn cores drilled adjacent to Kohnen station by 


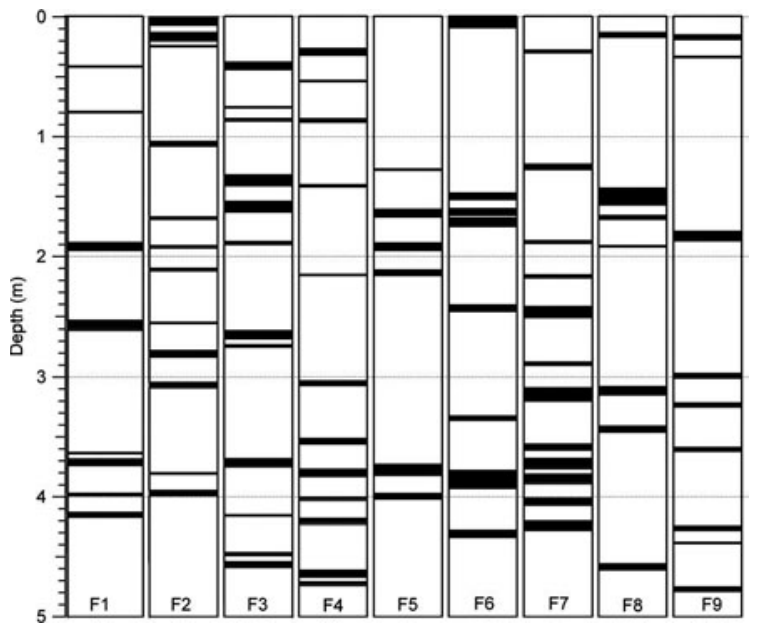

Fig. 4. Dune horizons (black horizontal bars of different thickness) in nine firn cores (F1-F9) covering a time interval of $22 \pm 2$ years. The cores were drilled along a $600 \mathrm{~m}$ long traverse route. The number of dune layers varies between 6 and 12 .

visual inspection of the specific pore structure of the snow and firn. Furthermore, the pore structure of newly formed dunes was compared with the pore structure in the vertically cut core sections. The pores in dune layers were always small and well intraconnected. The ice matrix was very hard, and during cutting the pores were filled with sawdust. Dune layers had sharp boundaries to the neighbouring firn. The thickness of the dune layers in the nine firn cores was $4 \pm 2 \mathrm{~cm}$. We identified $6-12$ buried dune layers per core (Fig. 4). The volume fraction of buried dune layers was $\sim 8 \%$. The dune horizons were randomly located within the firn cores. There was no depth correlation between the dune horizons in different firn cores. This reflects a relatively low coverage of the surface by dunes formed during a single event, which supports our observations during the 2005/06 summer.

The firn cores covered a time interval of $22 \pm 2$ years, if we assume a mean annual accumulation rate of $64 \mathrm{~mm}$ w.e. $\mathrm{a}^{-1}$ (EPICA Community Members, 2006). With a spatial dune coverage of $5-15 \%$ after a dune formation event and the assumption that dunes once formed will be buried and not eroded again by a subsequent storm, we calculate three to eight dune formation events per year for the area around Kohnen station.

\section{OBSERVATIONS: STRONG-WIND EVENTS AND FORMATION OF DUNES}

In DML, the near-surface climate is mainly determined by katabatic winds and transient cyclones. The long-term average of $2 \mathrm{~m}$ wind speed measured at the Utrecht University/IMAU automatic weather station (AWS) No. 9 (AWS9) in the vicinity of Kohnen station is $4.5 \mathrm{~m} \mathrm{~s}^{-1}$ (Reijmer and Van den Broeke, 2003). All three events of barchan-type snow-dune formation observed during the 2005/06 summer campaign were characterized by comparatively heavy snowdrift and a mean $2 \mathrm{~m}$ wind speed at AWS9 slightly higher than $10.0 \mathrm{~ms}^{-1}$ for 4 hours in two cases and 6 hours in one case. During the whole campaign, such high wind speeds occurred only during these three dune formation events.

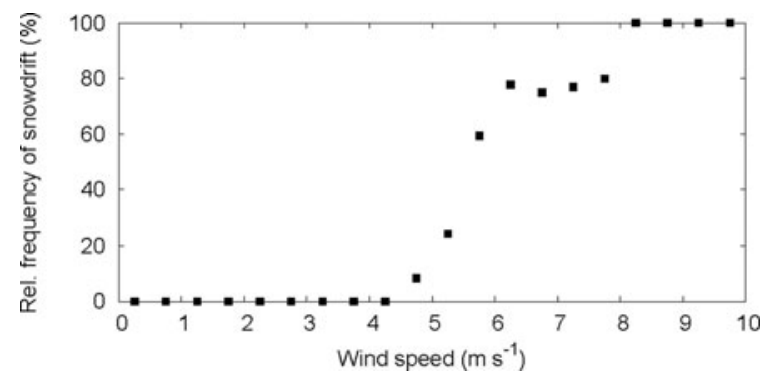

Fig. 5. Relative frequency of observed snowdrift as function of 1 hour mean wind speed at $2 \mathrm{~m}$ height at AWS9 in the 2005/06 austral summer.

Based on 408 visual observations (made mainly at 3 hourly intervals, except during night-time at Kohnen station) from mid-November 2005 to the beginning of February 2006, Figure 5 shows the relative frequency of snowdrift as a function of hourly mean $2 \mathrm{~m}$ wind speed measured at AWS9. Mean wind speeds $<5.0 \mathrm{~m} \mathrm{~s}^{-1}$ did not cause snowdrift. During most periods with snowdrift, the maximum hourly mean $2 \mathrm{~m}$ wind speed at AWS9 did not exceed $8.0 \mathrm{~m} \mathrm{~s}^{-1}$. We experienced three snowdrift events on days with maximum hourly mean $2 \mathrm{~m}$ wind speeds of 8.0 $9.0 \mathrm{~m} \mathrm{~s}^{-1}$ and one event on a day with speeds of $9.3 \mathrm{~m} \mathrm{~s}^{-1}$. The barchans, however, only formed when the mean $2 \mathrm{~m}$ wind speed was $>10.0 \mathrm{~m} \mathrm{~s}^{-1}$ for at least 2 hours. These results agree with Braaten's (2000) finding that the threshold wind speed for saltation typically ranges from 6.0 to $10.0 \mathrm{~m} \mathrm{~s}^{-1}$ depending on snow surface conditions.

In the three dune formation events observed, a period of about 2 hours with wind speeds $>10.0 \mathrm{~m} \mathrm{~s}^{-1}$ was sufficient to form the general structure of the barchans. During the rest of the snowdrift period, the dunes no longer grew, but moved, propagating leeward at a few $\mathrm{cm} \mathrm{min}{ }^{-1}$. Snowdrift ended at mean wind speeds significantly less than $10.0 \mathrm{~m} \mathrm{~s}^{-1}$. However, this was always the case on the day of dune formation. Our observations are in good agreement with findings by Mann and others (2000) who point out that two thresholds are referred to in aeolian particle transport. The fluid threshold is the speed required to initiate the process from a state of rest. The impact threshold is that required to maintain transport when in motion. Once an episode has begun, particles continually bombard the surface, providing energy to help maintain the process. Hence, the impact threshold is assumed to be less than the fluid threshold (e.g. Schmidt, 1980).

The $2 \mathrm{~m}$ wind speed was comparatively high, with 2 hour mean values generally $6.0-9.0 \mathrm{~m} \mathrm{~s}^{-1}$ on two days prior to dune formation on 9 December 2005 and 28 January 2006, and on three days prior to dune formation on 11 January 2006. On these days prior to the formation events, snowdrift was already observed.

On 8-10 January 2006 and 26-27 January 2006, light snowfall occurred. However, based on observations from numerous previous expeditions to Antarctica we suppose that these newly fallen snow crystals were too light to move in the process of saltation and that the snow dunes were formed out of older, heavier snow particles lifted from the ground (see description above). During saltation the snow particles also become rounder, making settling more efficient. Prior to every day with dune formation, a large amount of loose, heavy particles was generated at the 
surface in the process of snowdrift. This appears to be a crucial prerequisite for dune formation on the following day. On the days of dune formation, the older snow was redistributed into snow dunes, caused by the high wind speeds. On all three days with snow-dune formation, snowfall no longer occurred; in one case, diamond dust was observed.

\section{SELECTION OF STRONG-WIND EVENTS}

To learn more about wind events that may have resulted in the formation of snow dunes in the Kohnen station area in recent years, we analyze time series of $2 \mathrm{~m}$ wind speed measured at AWS9. AWS9 measurements started in December 1997. A 7 year period of data from the years 1998-2000 and 2002-05 is used for the present investigation, as no reliable data exist for 2001 due to several instrument failures. Taking into account our observations and previous findings from the above-mentioned literature, a strong-wind event that may have led to the formation of snow dunes is defined in the present study by the following criteria:

1. An event starts when the 2 hour mean AWS wind speed exceeds $10.0 \mathrm{~m} \mathrm{~s}^{-1}$ for the first time.

2. An event ends when the 2 hour mean AWS wind speed drops below $10.0 \mathrm{~m} \mathrm{~s}^{-1}$.

3. Two periods meeting conditions (1) and (2) are considered as one event in case the 2 hour mean AWS wind speed does not drop below $5.0 \mathrm{~m} \mathrm{~s}^{-1}$ during an interval of $<24$ hours between the two periods.

In the 7 year period 1998-2000/2002-05, exactly 100 events were identified by means of the AWS9 data, that meet the definition of a strong-wind event given above. The number of events per year varied between 11 and 19. The frequency of events was largest in winter (June-August), when $38 \%$ of all cases occurred, with $25 \%$ in spring (September-November), 18\% in summer (December-February) and $19 \%$ in fall (March-May). The duration of an event varied between 2 and 96 hours. However, 50\% of all events did not last longer than 12 hours. This indicates that the three events visually observed in summer 2005/06 were quite common; they belong to the group of shortest, although most frequently occurring, strong-wind events at Kohnen station.

During $85 \%$ of the events the 2 hour mean AWS wind speed did not exceed $16.0 \mathrm{~m} \mathrm{~s}^{-1}$, the threshold value given by Kobayashi and Ishida (1979) for the change from the formation of transverse dunes (barchans) to the formation of longitudinal dunes (values above this threshold). Only 15\% of the events had a maximum 2 hour mean wind speed between 16.0 and $23.0 \mathrm{~m} \mathrm{~s}^{-1}$. The maximum 2 hour mean wind speed of the three events observed in summer 2005/06 ranged from 10.3 to $10.7 \mathrm{~m} \mathrm{~s}^{-1}$.

As discussed in detail later, strong-wind events at Kohnen station are caused by the influence of low-pressure systems, which direct maritime air masses over DML. None of the events is associated with enhanced katabatic flow.

On average, we detected 14.3 strong-wind events per year at Kohnen station in the 7 year period 1998-2000/ 2002-05. This is considerably more than the 3-8 dunes per year buried in the firn in the period 1983-2005. There are several possible reasons for this discrepancy. One reason could be a missing particle supply during some strong-wind events, which would reduce or prevent dune formation. Andreotti and others (2002) point out that the mobile particles must appear in patches of a certain size to act as nucleation points for dune formation. The dimensions of such particle patches must be larger than the saturation length, which is the length needed for particle transport to reach equilibrium with the wind strength. In the case of the observed snow dunes, the particle patches must only have had a dimension of the order of meters. In spite of some large glazed surface areas, it is not very likely that there is a lack of particle supply for dune formation on the Antarctic plateau. A second reason could be an uncertainty in the estimate of the dune coverage after a strong-wind event. Our observations were limited to events with wind speeds only slightly higher than the lower limit for strong wind. It cannot be excluded that the observed values of $5-15 \%$ dune coverage of the surface area would be smaller for dunes formed during stronger winds. A smaller value of dune coverage would, however, increase the number of dune formation events derived from the firn-core studies. A third reason for the discrepancy could be that the identified dune layers in the firn cores represent dunes formed only under specific conditions during strong-wind events. As already mentioned, the dune layers in the firn cores had been selected by their density, hardness and particle connectivity as found in dunes formed from redistributed snow in the observation period. The newly formed dunes had densities up to $30 \%$ higher than the mean surface density. The same holds for the identified layers in the firn cores in relation to the average densities in a certain depth interval. The dunes at the surface were also similar to the selected layers in the cores in regard to hardness and inner particle connectivity (Freitag and others, 2008). Taking this into account, all selected layers in the firn cores could be identified as buried dunes originally formed by redistributed snow. Because the dune statistics underestimate the number of strong-wind events, a further meteorological condition in addition to strong wind must be fulfilled so that these dunes can form and harden.

As described above, in none of the three cases of barchan-type snow-dune formation observed in the 2005/ 06 austral summer did snowfall occur on the day of dune formation. (Only diamond dust was observed in one case.) Although we only studied three short strong-wind events with dune formation in detail, we conclude that the absence of snowfall in the last period of snowdrift and when the dunes reach their final position is an important condition for the fast hardening of the newly formed dunes. Newly fallen snow in dunes would lead to a lower initial density of the dunes, hence the dunes would possibly erode again. Our conclusion is supported by Kobayashi and Ishida (1979), who found that barchans commonly form when previously deposited snow is redistributed by a dry wind, whereas longitudinal dunes are associated with very strong winds blowing during the passage of a cyclonic snowstorm, at which time much new snow is deposited.

\section{EVENTS THAT MAY HAVE CAUSED SNOW-DUNE FORMATION}

We now consider the absence of snowfall on the day when the dunes reach their final position (in the case of short strong-wind events, on the day of the event itself; in the case of longer strong-wind events, on the last day of the event) as 
Table 1. Correlation coefficients between the time series of daily mean wind speed derived from AWS9 measurements and the time series of daily mean wind speed derived from NCEP/NCAR reanalysis, ERA-40 and AMPS forecasts, respectively

Period

Correlation coefficient

NCEP-AWS ERA-40-AWS AMPS-AWS

\section{Entire period}

1998-2000

2002-05

0.53

0.50

0.79

Days of strong-wind events 1998-2000

2002-05

0.68

0.64

0.80

0.87 a prerequisite for the fast hardening of the barchans and for their preservation in the firn, and we calculate the number of strong-wind events which fulfill this criterion. For this investigation we use time series of model-generated daily precipitation rate. We employ data of the US National Centers for Environmental Prediction/National Center for Atmospheric Research (NCEP/NCAR) reanalysis (Kalnay and others, 1996), of the European Centre for Medium-Range Weather Forecasts (ECMWF) reanalysis ERA-40 (Uppala and others, 2005), and of forecasts of the Antarctic Mesoscale Prediction System (AMPS), which, however, are only available since January 2001. AMPS (Powers and others, 2003; Bromwich and others, 2005) provides numerical weather forecasts especially for Antarctica, mainly in support of flight operations and scientific activities of the United States Antarctic Program. AMPS was developed by the NCAR and the Polar Meteorology Group of the Byrd Polar Research Center (BPRC) of The Ohio State University. For the period investigated in the present study, AMPS employed a version of the MM5 (the 'Polar MM5') mainly with a horizontal grid spacing of $30 \mathrm{~km}$ in DML; in September 2005 the spacing changed to $20 \mathrm{~km}$. The Polar MM5 is a version of the Fifth-Generation Pennsylvania State University/NCAR Mesoscale Model optimized for use in polar regions.

Before analyzing the time series of daily precipitation rate, we have to check the time series of model-generated nearsurface wind speed in regard to the occurrence of periods with comparatively high wind speed when AWS9 data indicate a strong-wind event. Because the temporal resolution of the reanalyses and forecast datasets is lower than the resolution of AWS9 data, the comparison of measured and modeled time series of near-surface wind speed is based on daily mean values. The time series of daily mean $2 \mathrm{~m}$ wind speed measured at AWS9 is now compared to time series of daily mean near-surface wind provided by NCEP/NCAR reanalysis, ECMWF reanalysis ERA-40, and AMPS 12 hour forecasts. NCEP/NCAR reanalysis and ERA-40 data are provided at $10 \mathrm{~m}$ height. They are taken from the gridpoint with the minimum distance to Kohnen, i.e. at $75.2^{\circ} \mathrm{S}, 0.0^{\circ} \mathrm{E}$ in the NCEP/NCAR dataset and at $75.0^{\circ} \mathrm{S}, 0.0^{\circ} \mathrm{E}$ in ERA-40. The AMPS forecast data also represent near-surface winds (horizontal wind at the lowest model half-sigma level, corresponding to about 12-14 $\mathrm{m}$ above the ground), and they were interpolated to the geographical position $75.0^{\circ} \mathrm{S}$, $0.0^{\circ} \mathrm{E}$. The comparison with NCEP/NCAR refers to the whole period 1998-2000/2002-05. The comparison with ERA-40 only refers to 1998-2000, since ERA-40 ends in 2002. Similarly, because AMPS only started in 2001, we analyze AMPS data from 2002 to 2005. We emphasize that data measured at AWS9 during the period investigated were not put into the Global Telecommunication System, the global network for the transmission of meteorological data to numerical weather-prediction centers.

Table 1 shows correlation coefficients between the time series of daily mean wind speed derived from AWS9 measurements and the time series of daily mean wind speed derived from NCEP/NCAR reanalysis, ERA-40 and AMPS forecasts, respectively. Daily variations in measured near-surface wind speed are much better captured in ERA40 and AMPS forecasts than in the NCEP/NCAR reanalysis. However, for our investigation it is most important that the correlation coefficient between measured and modeled data is high on days with strong wind. Therefore, we select all days from AWS9 data, NCEP/NCAR reanalysis, ERA-40 and AMPS forecasts when AWS9 indicates a strong-wind event. For this subset of the whole time series of daily mean wind speed, the correlation coefficient improves considerably for NCEP/NCAR reanalysis and AMPS forecast data (Table 1). The correlation coefficient between AWS9 and ERA-40 data improves only slightly. The highest correlation coefficient for the days of strong-wind events results for the AMPS forecasts. The correlation coefficient is 0.87 in this case. The results show that the numerical models predict strong low-pressure systems particularly well. The comparison of time series of daily mean wind speed derived from AWS9 measurements and AMPS forecasts is illustrated in Figure 6a for the year 2002. Note that an exact quantitative agreement of wind time series compared cannot be expected, because they refer to slightly different height levels and AMPS forecast data are interpolated values from a model grid.

A detailed analysis for all 100 strong-wind events identified shows that the NCEP/NCAR reanalysis fails to reproduce on average two periods per year with comparatively high daily mean wind speeds which are associated with one of the 11-19 strong-wind events per year identified on the basis of 2 hour mean values of wind speed measured at AWS9. ERA-40 misses two periods in 1998, but none in 1999 and 2000. In the years 2002-05, AMPS was able to reproduce all periods with high daily mean wind speed when AWS9 measurements indicate a strong-wind event. We conclude that the number and seasonal distribution of strong-wind events at Kohnen station as derived from AWS9 measurements are captured very well in ERA-40 as well as AMPS forecasts.

We now derive time series of daily precipitation rate from the NCEP/NCAR reanalysis, the ERA-40 reanalysis and the AMPS forecasts for the same periods and locations as for the comparison of wind speeds. As mentioned above, we aim to select all those strong-wind events that were associated with either no snowfall or only diamond dust (weak precipitation) on the day when the strong wind ends.

We assume that NCEP/NCAR reanalysis underestimates the precipitation rate on days with weak and moderate precipitation, so daily precipitation rates from the NCEP/ NCAR reanalysis are not used in further investigations. This decision is based on a comparison of the annual sum of precipitation derived from the NCEP/NCAR reanalysis at the model gridpoint at $75.2^{\circ} \mathrm{S}, 0.0^{\circ} \mathrm{E}$ close to Kohnen station 

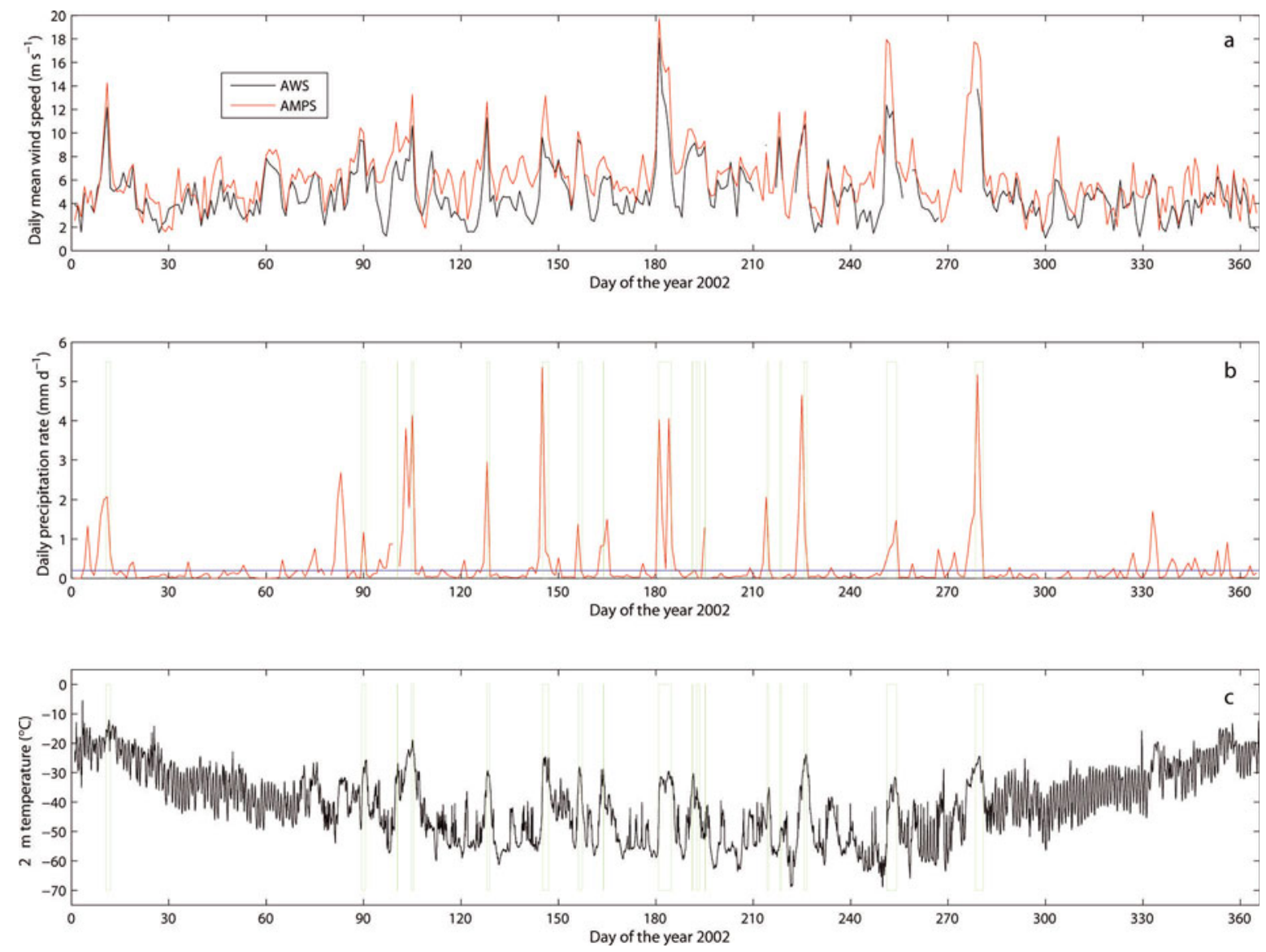

Fig. 6. (a) Time series of daily mean wind speed derived from AWS9 data (black) and AMPS forecast data (red) for 2002. (b) Time series of daily precipitation rate derived from AMPS forecast data (red) for 2002. Periods of strong-wind events identified on the basis of 2 hour mean values of wind speed measured at AWS9 are indicated by green rectangles. The blue line indicates a daily precipitation rate of $0.2 \mathrm{~mm}$ w.e. $\mathrm{d}^{-1}$. (c) Time series of 2 hour mean temperature at $2 \mathrm{~m}$ height at AWS9 (black) for 2002. Periods of strong-wind events identified on the basis of 2 hour mean values of wind speed measured at AWS9 are indicated by green rectangles.

with the long-term mean value of $64 \mathrm{~mm}$ w.e. $\mathrm{a}^{-1}$ for the annual accumulation resulting from glaciological measurements at Kohnen station (EPICA Community Members, 2006). For the period 1998-2000/2002-05, the lowest and the highest annual sums of precipitation calculated from the NCEP/NCAR reanalysis were in $2004\left(12 \mathrm{~mm}\right.$ w.e. $\left.\mathrm{a}^{-1}\right)$ and $2003\left(30 \mathrm{~mm}\right.$ w.e. $\left.\mathrm{a}^{-1}\right)$, respectively. Because daily precipitation rates during high-precipitation events are quite realistic in the NCEP/NCAR reanalysis, the rate on days with weak and moderate precipitation must be underestimated. The same comparison was performed with ERA40 data and with AMPS forecast data. The annual sum of precipitation derived from ERA-40 data is 49, 65 and $33 \mathrm{~mm}$ w.e. $\mathrm{a}^{-1}$, respectively, for the three years 1998-2000. The annual sum of precipitation derived from AMPS forecast data is $108,71,69$ and $77 \mathrm{~mm}$ w.e. $\mathrm{a}^{-1}$, respectively, for the four years 2002-05. In both cases, the calculated values agree reasonably well with the measured long-term mean annual accumulation of $64 \mathrm{~mm}$ w.e. $\mathrm{a}^{-1}$. However, AMPS forecasts generally seem to simulate more precipitation than ERA-40.

Based on the analysis of model-generated data, namely of the ECMWF reanalysis ERA-15 for the period 1979-93, and of the ECMWF operational archive for the years 1994-97, Noone and others (1999) define all days with $<0.2 \mathrm{~mm}$ w.e. precipitation in DML as days with weak precipitation (diamond dust). Figure $6 \mathrm{~b}$ shows the time series of daily precipitation rate from AMPS forecasts for 2002 together with the periods of strong-wind events identified on the basis of 2 hour mean values of wind speed measured at AWS9. Not all strong-wind events are associated with high daily precipitation rates and vice versa. For example, the precipitation rate on day 218 of the year is $0 \mathrm{~mm}$ w.e. $\mathrm{d}^{-1}$, although a strong-wind event of 10 hours length occurred on that day. Furthermore, it is clear that certain peaks in the time series of daily precipitation rate appear prior to or at the beginning of a strong-wind event. For example, the strong-wind event from 0400 UTC on 5 June 2002 to 0800 UTC on 6 June 2002 (days 156 and 157 of the year) was associated with a precipitation rate of $1.4 \mathrm{~mm}$ w.e. $\mathrm{d}^{-1}$ on the first day, but with a rate of only $0.03 \mathrm{~mm}$ w.e. $\mathrm{d}^{-1}$ on the second day.

Following the definition by Noone and others (1999), we now select all strong-wind events from the ERA-40 reanalysis data (1998-2000) and the AMPS forecasts (2002-05) that fulfill the condition that on the day when the strong-wind event ends, the precipitation rate is $<0.2 \mathrm{~mm}$ w.e. $\mathrm{d}^{-1}$. On average, ERA-40 reveals 6.0 , and the AMPS forecasts reveals 3.75, such cases per year, which we consider to cause barchan-type dune formation. Both values are in the range $3-8$, the derived number of snow dunes per year that were preserved in the firn in the Kohnen station area. The seasonal distribution of the dune formation events is $18.2 \%$ in fall, $33.3 \%$ in winter, $39.4 \%$ in spring and $9.1 \%$ in summer. 


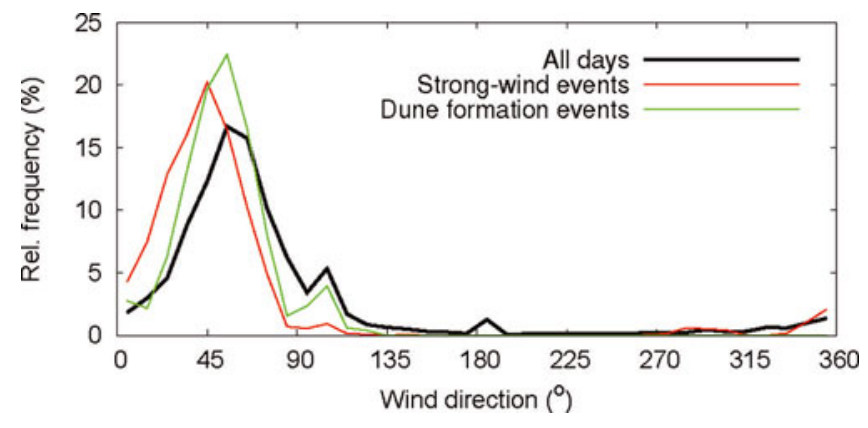

Fig. 7. Relative frequency of 2 hour mean wind direction at $2 \mathrm{~m}$ height at AWS9 in the whole period 1998-2000/2002-05 (black curve), during all strong-wind events (red curve) and during all barchan-type dune formation events (green curve).

\section{CHARACTERISTICS OF STRONG-WIND AND DUNE FORMATION EVENTS}

All strong-wind and, hence, all barchan-type dune formation events at Kohnen station identified in the 7 year period 1998-2000/2002-05 are caused by the influence of a lowpressure system. The tracks of these low-pressure systems are discussed in section 8 . Here we characterize the impact of these systems on the meteorological conditions at Kohnen station.

The long-term average of wind direction measured at $2 \mathrm{~m}$ height at AWS9 is $57^{\circ}$ with a directional constancy of 0.88 (Reijmer and Van den Broeke, 2003). This high directional constancy reflects the persistent katabatic flow during most of the year. In the majority of strong-wind and dune formation events, the near-surface wind turned to the northeast or even further northwards, reflecting cyclonic activity as the main cause for unusually high wind speeds at Kohnen station (Fig. 7).

During strong-wind and dune formation events, maritime air masses are directed onto the plateau. This effect is clearly seen in the time series of near-surface temperature at Kohnen station. For example, Figure $6 \mathrm{c}$ shows time series of 2 hour mean temperature at $2 \mathrm{~m}$ height at AWS9 for 2002 together with the periods of strong-wind events identified on the basis of 2 hour mean values of wind speed measured at AWS9. Near-surface temperature rises considerably (up to tens of ${ }^{\circ} \mathrm{C}$ ) during strong-wind events. As already pointed out by Van As and others (2007), the temperature increase is partly caused by the advection of heat, but a significant part is also caused by the destruction of the stable temperature-deficit layer by enhanced vertical mixing. The temperature rise is larger during winter than during summer, due to a betterdeveloped temperature deficit in winter.

The low-pressure systems influencing the Kohnen station area are of different intensity, and pass DML at different distances. Hence, their impact on the Kohnen station area varies with respect to the entire duration, maximum wind speed and total sum of precipitation of a strong-wind event. As shown in Table 2, 57\% of all strong-wind events are associated with maximum 2 hour mean wind speeds at AWS9 of only $10.0-12.0 \mathrm{~m} \mathrm{~s}^{-1}$. These events have the shortest duration and give the lowest sum of precipitation. The stronger the influence of a low-pressure system, the longer, on average, is the duration of an associated strongwind event, the higher is the maximum wind speed and the higher is the total sum of precipitation. The percentages of
Table 2. Features of strong-wind events in the periods 1998-2000 and 2002-05. The number of strong-wind events, their average duration and the average sum of precipitation they caused are given for four intervals of the maximum 2 hour mean wind speed at $2 \mathrm{~m}$ height, $v_{m}$, at AWS9 during an event. The precipitation is calculated based on daily precipitation rates derived from ERA-40 and from AMPS forecasts, respectively

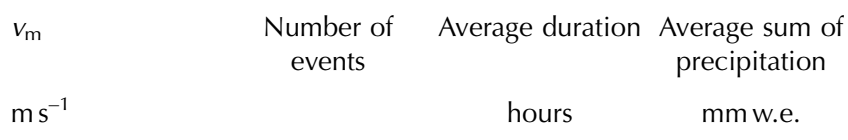

$1998-2000$

$10.0 \leq v_{\mathrm{m}}<12.0$

$12.0 \leq v_{\mathrm{m}}<14.0$

$14.0 \leq v_{\mathrm{m}}<16.0$

$16.0 \leq v_{\mathrm{m}}$

$\begin{array}{rrl}23 & 8.0 & 0.35 \\ 11 & 26.0 & 0.88 \\ 5 & 43.6 & 2.23 \\ 9 & 51.1 & 2.46 \\ & & \\ 34 & 8.7 & 1.0 \\ 7 & 33.1 & 2.72 \\ 5 & 50.4 & 3.08 \\ 6 & 55.7 & 6.64\end{array}$

barchan-type dune formation events in the whole period 1998-2000/2002-05 are $42 \%$ in the interval $10.0 \mathrm{~m} \mathrm{~s}^{-1} \leq v_{\mathrm{m}}<12.0 \mathrm{~m} \mathrm{~s}^{-1}, 39 \%$ in the interval $12.0 \mathrm{~m} \mathrm{~s}^{-1}$ $\leq v_{\mathrm{m}}<14.0 \mathrm{~m} \mathrm{~s}^{-1}$, and $20 \%$ in the interval $14.0 \mathrm{~m} \mathrm{~s}^{-1}$ $\leq v_{\mathrm{m}}<16.0 \mathrm{~m} \mathrm{~s}^{-1}$, where $v_{\mathrm{m}}$ is the maximum 2 hour mean wind speed at $2 \mathrm{~m}$ height at AWS9 during the event. The values in Table 2 again show the previously mentioned fact that AMPS simulates more precipitation than ERA-40 during the influence of low-pressure systems on the Kohnen station area.

The characteristics of strong-wind events discussed imply that enhanced katabatic flow is not the reason for unusually high near-surface wind speeds at Kohnen station, which is in accordance with the findings by Van As and others (2007) that the largest near-surface wind speeds at Kohnen station are caused by strong large-scale forcing.

\section{SYNOPTIC DEVELOPMENTS CAUSING STRONG- WIND AND DUNE FORMATION EVENTS}

Based on forecast products by ECMWF and AMPS as well as Advanced Very High Resolution Radiometer (AVHRR) satellite images continuously received at Neumayer station $\left(70^{\circ} 39^{\prime} \mathrm{S}, 08^{\circ} 15^{\prime} \mathrm{W}, \sim 600 \mathrm{~km}\right.$ north of Kohnen station), the synoptic developments that led to the strong-wind events identified were analyzed. $80 \%$ of all events were caused by synoptic evolutions, which belong to the following four categories (Fig. 8):

\section{Category I:}

Lows which first move from the Antarctic Peninsula/ northern Weddell Sea southeastwards to a position close to Neumayer station and then continue to move to the east or northeast. ( $42 \%$ of events)

\section{Category II:}

Lows initially situated off the coast east of the Greenwich meridian, which move to the west (retrograde movement) along the ice-shelf edge. (14\% of events) 

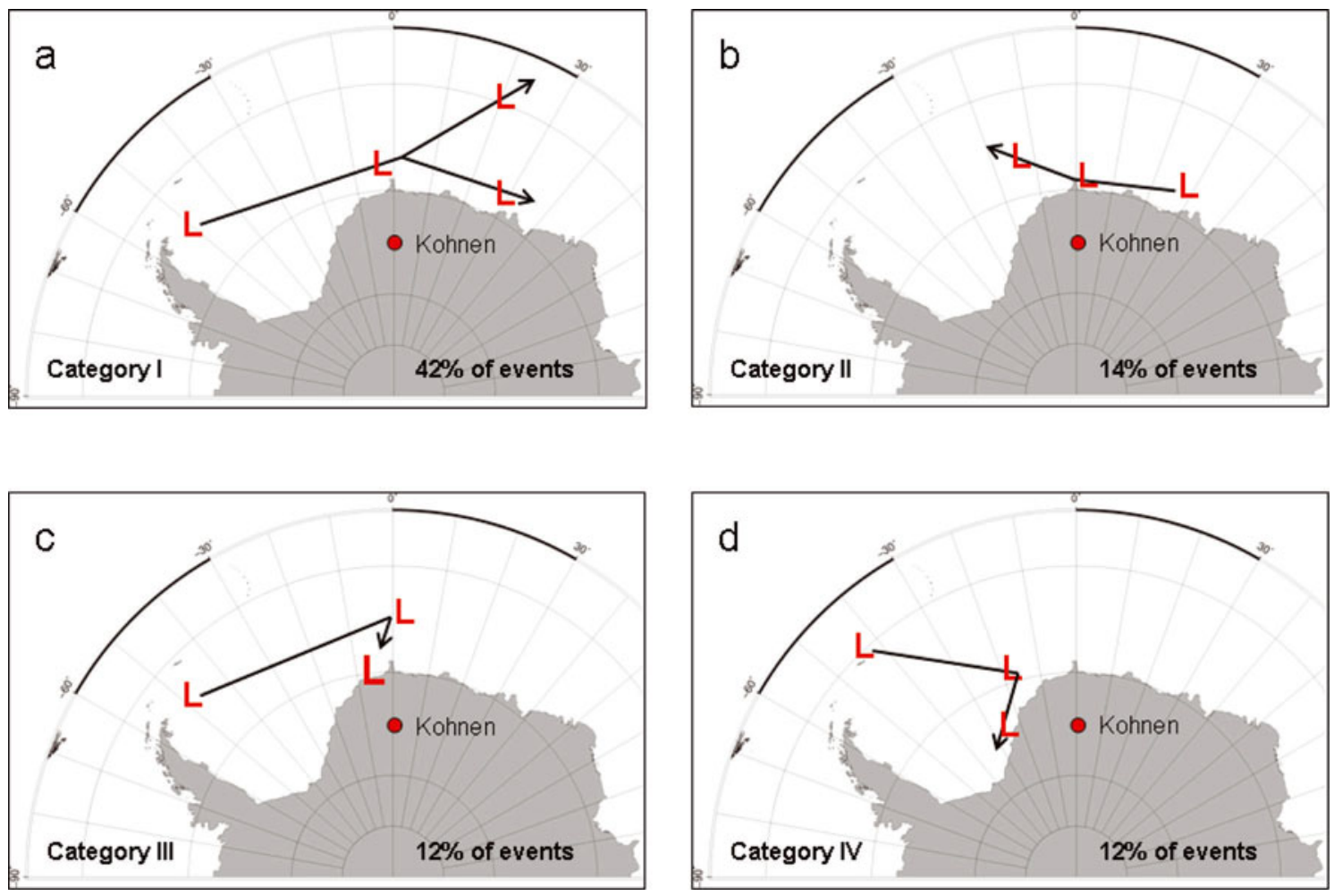

Fig. 8. Synoptic developments causing strong-wind events at Kohnen station: pattern for category I (a), category II (b), category III (c) and category IV (d). The red character $\mathrm{L}$ indicates the center of a low-pressure system. The black straight lines and arrows show the track of a lowpressure system in a simplified way.

\section{Category III:}

Lows which move from the Antarctic Peninsula/northern Weddell Sea southeastwards to a position close to Neumayer station and become stationary there. $(12 \%$ of events)

\section{Category IV:}

Lows which first move from the Antarctic Peninsula/ northern Weddell Sea southeastwards, then turn southwest and fill up close to Halley station or the Filchner Ice Shelf. (12\% of events)

The remaining $20 \%$ of events show different synoptic evolutions, but their number is too small to further categorize them. This categorization confirms the basic finding by Van As and others (2007) that most strong-wind events at Kohnen station are caused by cyclones in the northeastern Weddell Sea.

The percentage of barchan dune formation events is quite similar to the percentage of strong-wind events in each of those categories. Hence, every synoptic development described above can lead to dune formation. None of the categorized tracks of low-pressure systems causing strongwind events is particularly typical for a certain season. The number of dune formation events is too small to derive a reliable conclusion on the seasonal distribution of events in each category (Table 3).

To illustrate the categorization given above, we finally discuss the visually observed barchan-type dune formation event on 11 January 2006 in more detail. This event was typical for category IV. The center of a low-pressure area moved from a position northeast of the Antarctic Peninsula on 9 January 2006 (Fig. 9a) towards the region northwest of Cape Norwegia by 11 January 2006 (Fig. 9b and c). The gale center with a surface pressure below $975 \mathrm{hPa}$ and the high on the Antarctic plateau southeast of Kohnen station caused a strong pressure gradient on 11 January 2006 and led to the high wind speeds at Kohnen station in the morning and around noon. In the following hours, the center of the lowpressure area moved southeastwards. Finally, it reached a position in the southeastern Weddell Sea close to Halley Station on 12 January 2006 (Fig. 9d) and filled up.

Table 3. Number of strong-wind events and barchan dune formation events in the entire period 1998-2000/2002-05 in each category describing different synoptic developments resulting in strong-wind events. Additionally, the seasonal distribution of the number of strong-wind events and dune formation events is given for the same categories

$$
\begin{aligned}
& \text { Number } \\
& \text { of events }
\end{aligned}
$$

\begin{tabular}{|c|c|c|c|c|c|}
\hline \multicolumn{6}{|c|}{ Strong-wind events } \\
\hline Cat. I & 42 & 6 & 14 & 15 & 7 \\
\hline Cat. II & 14 & 2 & 9 & 1 & 2 \\
\hline Cat. III & 12 & 5 & 4 & 1 & 2 \\
\hline Cat. IV & 12 & 2 & 4 & 3 & 3 \\
\hline Other & 20 & 4 & 7 & 5 & 4 \\
\hline \multicolumn{6}{|c|}{ Dune formation events } \\
\hline Cat. I & 15 & 2 & 4 & 8 & 1 \\
\hline Cat. II & 6 & 1 & 5 & 0 & 0 \\
\hline Cat. III & 3 & 2 & 1 & 0 & 0 \\
\hline Cat. IV & 2 & 0 & 0 & 1 & 1 \\
\hline Other & 7 & 1 & 1 & 4 & 1 \\
\hline
\end{tabular}

Fall Winter Spring Summer 

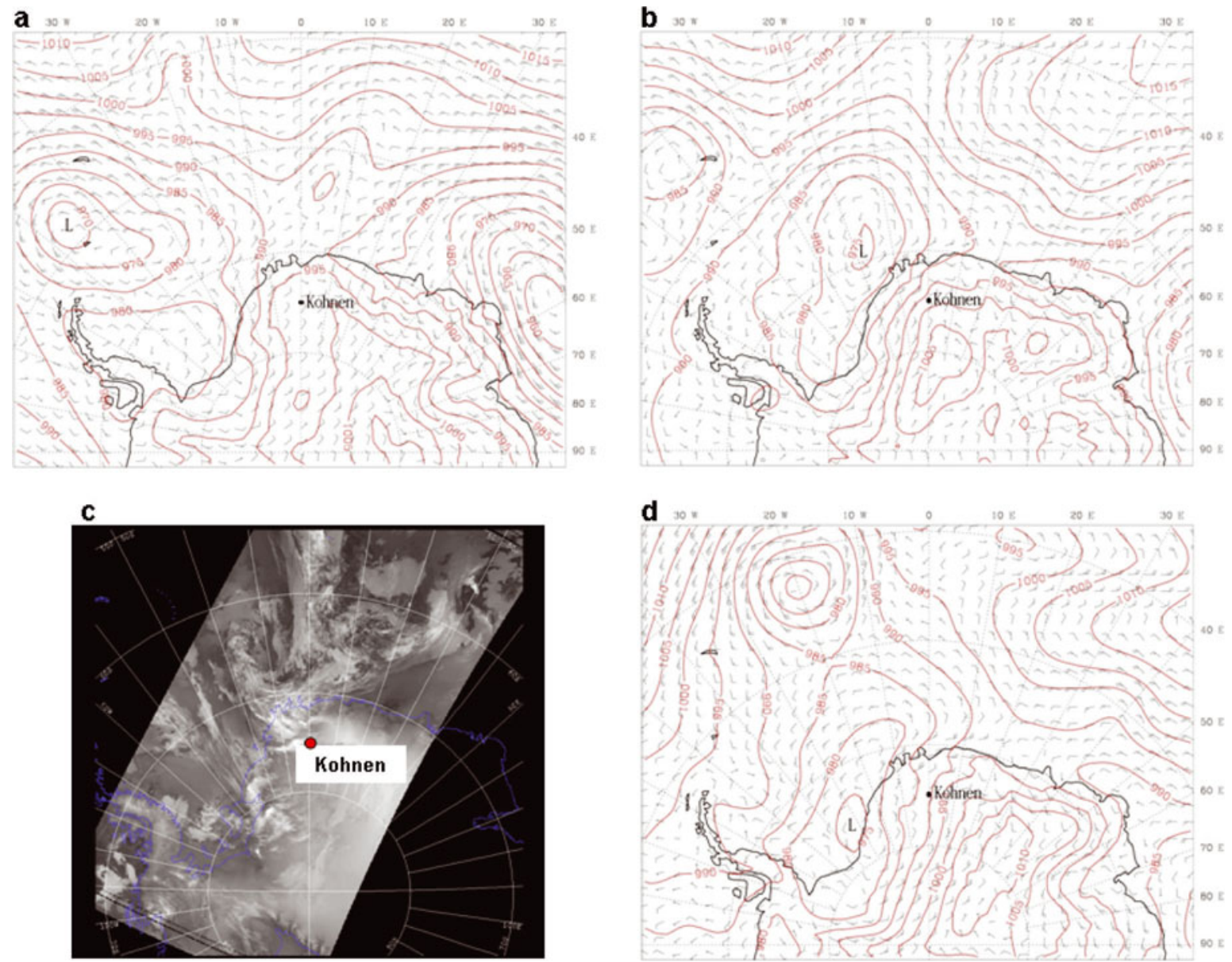

Fig. 9. $(a, b, d)$ Sea-level pressure and near-surface horizontal wind vectors (full barb indicates $5 \mathrm{~m} \mathrm{~s}^{-1}$ ) provided by AMPS analysis at 0000 UTC: (a) on 9 January 2006, (b) on 11 January 2006 and (d) on 12 January 2006. The black letter L indicates the center of a low-pressure system. (c) AVHRR satellite image in the infrared range on 11 January 2006, 0309 UTC. The coastline of Antarctica and the inner boundary of the ice shelves are indicated in blue.

\section{SUMMARY AND CONCLUSIONS}

We showed that synoptic processes over the Weddell Sea influence accumulation patterns on the Antarctic plateau of DML. Low-pressure systems in near-coastal locations can lead to strong near-surface winds on the plateau, which favor snowdrift and under certain conditions the formation of snow dunes, especially barchans. However, the barchans do not change the accumulation in a larger area; rather, they redistribute the snow on the decameter scale.

At Kohnen station, the EPICA deep ice-core drilling site in $\mathrm{DML}$, three barchan-type snow-dune formation events were observed during the 2005/06 austral summer. The main characteristics of all the events were: (1) a comparatively long phase of 2 or 3 days with snowdrift prior to dune formation; (2) dunes formed only during periods with wind speeds of $>10 \mathrm{~m} \mathrm{~s}^{-1}$ at $2 \mathrm{~m}$ height on days with no snowfall; and (3) the high near-surface wind speeds were caused by the influence of low-pressure systems, not by katabatic winds.

Typical synoptic developments for the occurrence of strong-wind events at Kohnen station were identified. The majority of events are caused by low-pressure systems, which move from the Antarctic Peninsula/northern Weddell Sea southeastwards to a position close to the continent north or northwest of Kohnen station before they influence the plateau area. An unexpectedly high number, 14\%, of strongwind events is associated with lows moving retrogradely from a position east of the Greenwich meridian to the west along the ice-shelf edge. However, this result is consistent with findings by Birnbaum and others (2006) who show that frontal clouds of retrograde-moving lows or secondary lows can cause relatively high precipitation rates at Kohnen station. Hence, retrograde-moving lows have the potential to strongly influence the weather in the plateau region of DML.

Snow-dune layers from past formation events were also detected in shallow firn cores drilled adjacent to Kohnen station during the 2005/06 austral summer. In situ observations of a $5-15 \%$ areal surface coverage of dunes after a formation event, and the analysis of dune layers in nine firn cores covering a time interval of $22 \pm 2$ years, revealed that there were approximately 3-8 events per year during which snow dunes had formed and later been conserved in the firn. This number is considerably lower than the average number of 14.3 strong-wind events per year identified in AWS9 data in the 7 year period 1998-2000/2002-05.

Clearly, a simple relation between the annual number of strong-wind events and the annual number of dune layers in the firn does not exist. Further conditions seem to be important for the formation of dunes and their preservation in the firn. We conclude that dunes at Kohnen station are not formed from newly fallen snow, but from older, redistributed snow. However, the amount of in situ observations during dune formation events on the Antarctic 
plateau is very limited. For DML we lack information for all the non-summer months. Thresholds and criteria employed in the present study are based on very limited summer in situ observations. They might have to be changed for the analysis of dune formation in the other seasons. Future investigations should reveal further conditions important for the formation of dunes.

An important aspect for the interpretation of air inclusions in polar ice cores is the observed and unexpectedly large stratification of firn at a rather low-accumulation site (on average, $64 \mathrm{~mm}$ w.e. $\mathrm{a}^{-1}$ at Kohnen station). The stratification is mainly due to the buried snow dunes. This changes the traditional view that only high-accumulation sites are stratified firn locations (Landais and others, 2006). It implies that at sites with dune formation we encounter small convection zones of only a few meters. In the convection zone, the pore structure of the firn is permeable enough to allow complete mixing by advection. Snow dunes as a contributor to the high-density fraction reduce air circulation. Compared with a non-stratified firn column, the permeability is reduced to approximately one-half if we apply the power-law relationship between permeability and porosity derived by Freitag and others (2002). Furthermore, if the layering propagates downwards to the firn-ice transition, the occurrence of snow dunes could also affect the air entrapment. The high-density layers serve as a lid, isolating the air from the atmosphere in lower depths than is expected in non-stratified firn. It follows that the age difference between enclosed air and the surrounding ice at a location like Kohnen station becomes smaller than at sites with similar snow accumulation but without dune formation.

\section{ACKNOWLEDGEMENTS}

We thank all the scientists and technicans who worked at Kohnen station in the 2005/06 austral summer for their help in maintaining continuous visual observations and scientific measurements. We also thank the overwinterers M. Zöllner and A. Anastou for collecting operational weather-forecast material at Neumayer station.

\section{REFERENCES}

Andreotti, B., P. Claudin and S. Douady. 2002. Selection of dune shapes and velocities. Part 1: Dynamics of sand, wind and barchans. Eur. Phys. J., B28(3), 321-339.

Bagnold, R.A. 1941. The physics of blown sand and desert dunes. London, Methuen and Co.

Barnola, J.M., D. Raynaud, Y. Korotkevich and C. Lorius. 1987. Vostok ice core provides 160,000-year record of atmospheric $\mathrm{CO}_{2}$. Nature, 329(6138), 408-414.

Birnbaum, G., R. Brauner and H. Ries. 2006. Synoptic situations causing high precipitation rates on the Antarctic plateau: observations from Kohnen Station, Dronning Maud Land. Antarct. Sci., 18(2), 279-288.

Bourke, M.C. and A.S. Goudie. 2009. Varieties of barchan form in the Namib Desert and on Mars. Aeolian Res., 1(1-2), 45-54.

Braaten, D.A. 2000. Direct measurements of episodic snow accumulation on the Antarctic polar plateau. J. Geophys. Res., 105(D8), 10,119-10,128.

Bromwich, D.H., A.J. Monaghan, K.W. Manning and J.G. Powers. 2005. Real-time forecasting for the Antarctic: an evaluation of the Antarctic mesoscale prediction system (AMPS). Mon. Weather Rev., 133(3), 579-603.
Carleton, A.M. and D.A. Carpenter. 1990. Satellite climatology of 'polar lows' and broadscale climatic associations for the Southern Hemisphere. Int. J. Climatol., 10(3), 219-246.

EPICA Community Members. 2006. One-to-one coupling of glacial climate variability in Greenland and Antarctica. Nature, 444(7116), 195-198.

Fahnestock, M.A., T.A. Scambos, C.A. Shuman, R.J. Arthern, D.P. Winebrenner and R. Kwok. 2000. Snow megadune fields on the East Antarctic Plateau: extreme atmosphere-ice interaction. Geophys. Res. Lett., 27(22), 3719-3722.

Freitag, J., U. Dobrindt and J. Kipfstuhl. 2002. A new method for predicting transport properties of polar firn with respect to gases on the pore-space scale. Ann. Glaciol., 35, 538-544.

Freitag, J., S. Kipstuhl and S.H. Faria. 2008. The connectivity of crystallite agglomerates in low-density firn at Kohnen station, Dronning Maud Land, Antarctica. Ann. Glaciol., 49, 114-120.

Frezzotti, M., S. Gandolfi and S. Urbini. 2002. Snow megadunes in Antarctica: sedimentary structure and genesis. J. Geophys. Res., 107(D18), 4344. (10.1029/2001JD000673.)

Furukawa, T., K. Kamiyama and H. Maeno. 1996. Snow surface features along the traverse route from the coast to Dome Fuji Station, Queen Maud Land, Antarctica. Proc. NIPR Symp. Polar Meteorol. Glaciol., 10, 13-24.

Goodwin, I.D. 1990. Snow accumulation and surface topography in the katabatic zone of eastern Wilkes Land, Antarctica. Antarct. Sci., 2(3), 235-242.

Jouzel, J. and 12 others. 1997. Validity of the temperature reconstruction from water isotopes in ice cores. J. Geophys. Res., 102(C12), 26,471-26,487.

Kalnay, E. and 21 others. 1996. The NCEP/NCAR 40-year reanalysis project. Bull. Am. Meteorol. Soc., 77(3), 437-471.

Kawamura, K. and 17 others. 2007. Northern Hemisphere forcing of climatic cycles in Antarctica over the past 360,000 years. Nature, 448(7156), 912-916.

Kipfstuhl, S. and 6 others. 2006. Microstructure mapping: a new method for imaging deformation-induced microstructural features of ice on the grain scale. J. Glaciol., 52(178), 398-406.

Kobayashi, S. and T. Ishida. 1979. Interaction between wind and snow surface. Bound.-Layer Meteorol., 16(3), 35-47.

Koerner, R.M. 1971. A stratigraphic method of determining the snow accumulation rate at Plateau Station, Antarctica, and application to South Pole-Queen Maud Land Traverse 2, 19651966. In Crary, A.P., ed. Antarctic snow and ice studies II. Washington, DC, American Geophysical Union, 225-238. (Antarctic Research Series 16.)

Lambert, F. and 9 others. 2008. Dust-climate couplings over the past 800,000 years from the EPICA Dome C ice core. Nature, 452(7187), 616-619.

Landais, A. and 15 others. 2006. Firn-air $d^{15} \mathrm{~N}$ in modern polar sites and glacial-interglacial ice: a model-data mismatch during glacial periods in Antarctica? Quat. Sci. Rev., 25(1-2), 49-62.

Mann, G.W., P.S. Anderson and S.D. Mobbs. 2000. Profile measurements of blowing snow at Halley, Antarctica. J. Geophys. Res., 105(D19), 24,491-24,508.

Martinerie, P., D. Raynaud, D.M. Etheridge, J.M. Barnola and D. Mazaudier. 1992. Physical and climatic parameters which influence the air content of polar ice. Earth Planet. Sci. Lett., 112(1-4), 1-13.

Noone, D., J. Turner and R. Mulvaney. 1999. Atmospheric signals and characteristics of accumulation in Dronning Maud Land, Antarctica. J. Geophys. Res., 104(D16), 19,191-19,211.

Petit, J.R. and 18 others. 1999. Climate and atmospheric history of the past 420,000 years from the Vostok ice core, Antarctica. Nature, 399(6735), 429-436.

Pook, M. and L. Cowled. 1999. On the detection of weather systems over the Antarctic interior in the FROST analyses. Weather Forecast., 14(6), 920-929.

Powers, J.G., A.J. Monaghan, A.M. Cayette, D.H. Bromwich, Y.-H. Kuo and K.W. Manning. 2003. Real-time mesoscale 
modeling over Antarctica: the Antarctic Mesoscale Prediction System (AMPS). Bull. Am. Meteorol. Soc., 84(11), 1533-1545.

Redenbach, C., A. Särkkä, J. Freitag and K. Schladitz. 2009. Anisotropy analysis of pressed point processes. Adv. Stat. Anal., 93(3), 237-261.

Reijmer, C.H. and M.R. van den Broeke. 2003. Temporal and spatial variability of the surface mass balance in Dronning Maud Land, Antarctica, as derived from automatic weather stations. J. Glaciol., 49(167), 512-520

Rundle, A.S. 1971. Snow accumulation and firn stratigraphy on the East Antarctic plateau. In Crary, A.P., ed. Antarctic snow and ice studies II. Washington, DC, American Geophysical Union, 239-255. (Antarctic Research Series 16.)

Schmidt, R.A. 1980. Threshold wind-speeds and elastic impact in snow transport. J. Glaciol., 26(94), 453-467.
Sinclair, M.R. 1994. An objective cyclone climatology for the Southern Hemisphere. Mon. Weather Rev., 122(10), 2239-2256.

Spencer, M.K., R.B. Alley and J.J. Fitzpatrick. 2006. Developing a bubble number-density paleoclimatic indicator for glacier ice. J. Glaciol., 52(178), 358-364.

Uppala, S.M. and 45 others. 2005. The ERA-40 re-analysis. Q. J. $R$. Meteorol. Soc., 131(612), 2961-3212.

Van As, D., M.R. van den Broeke and M.M. Helsen. 2007. Strongwind events and their impact on the near-surface climate at Kohnen Station on the Antarctic Plateau. Antarct. Sci., 19(4), 507-519.

Watanabe, O. 1978. Distribution of surface features of snow cover in Mizuho Plateau. Mem. Natl Inst. Polar Res., Special Issue 7, 44-62.

MS received 25 January 2010 and accepted in revised form 27 August 2010 